\title{
Study on Operation Risk Assessment of Electric Power Enterprise based on Fuzzy Analytic Hierarchy Process
}

\author{
Fusen Zhong ${ }^{1,2, a}$, Chuanliang Jia ${ }^{1, b}$, Shiming Liu ${ }^{1, c}$, Jiali Tan $^{1, d}$ \\ ${ }^{1}$ School of Management Science and Engineering, Central University of Finance and Economics, \\ Beijing, 100081 ,China \\ ${ }^{2}$ National Power Grid Energy Research Institute,Beijing, 102209, China \\ aemail: zhongfs2005@163.com, bemail: cnbjjcl@163.com, \\ cemail:liushiming1991@163.com, cemail: tjl_carly@163.com
}

Keywords: Fuzzy set theory; AHP Perspective; Power Enterprise Operational Risk; Assessment

\begin{abstract}
Power Enterprise Operational risk is a major issue for the power companies. Based on the study of operational risk index system of domestic and international power companies, using the Delphi method to determine the power of operations risk assessment index, then using AHP and fuzzy set theory to determine the membership of each index for different evaluation results, and then calculating the weight of index set, and finally with the empirical analysis by way of illustration the main significance of the method. Power operational risk assessment system established by the AHP and fuzzy set theory grasp both the macro trends enterprise market as a whole, but also reflect the composition of the microscopic state of each market to better operational risks within the enterprise assess the situation and provide reference for decision-makers.
\end{abstract}

\section{Introduction}

With the further development of market economy, effective risk management can improve business efficiency and enhance core competitiveness of enterprises, while promoting sustainable and stable development. As a typical energy infrastructure industry, electricity has technology-intensive and capital-intensive feature, confronting many aspects of risk, such as technology, economics, management, forecasting, decision-making and so on. These risk factors will not only affect power companies their own, but also affect the people's livelihood and social harmony. From this perspective, the establishment of an effective management system of power enterprise operational risk to prevent and resolve risks that may arise in business operations has become a major issue which is looming. In this paper, based on combing research results of predecessors on enterprise operational risk, we build a new set of index system for the power companies to quantify and assess operational risk. Quantify and assess operational risk for power companies by AHP and fuzzy set theory to help companies realize the power of risk assessment, risk monitoring and risk warning and other aspects of the function.

\section{Literature Review}

Risk management appears really as a discipline marked by the publication of two books: Mehr (1963) "Enterprise Risk Management" and C.A. Williams (1964) "Risk Management and Insurance".

Domestic scholars have made some positive exploration on operational risk of the power companies. Hanfang Lee and etc. (2007) analyze the degree of impact on risk factors that exist in power grid enterprises operations, and put forward the corresponding operations risk assessment framework system. Jianhua Gong and etc. (2014) use decision method which is combined the gray correlation degree with TOPSIS to optimize the sorting for risk management indicators, and to further improve operations risk control indicators system of the power grid enterprises. Qishi Xiao and etc. (2014) construct a set of model of management system of company operational risk to monitor and analyze power grid enterprise operational risk situation, deepening management and 
control mechanisms of operational risk.

According to these research results, although scholars make a lot of theoretical and applied exploration on the power companies operations risk, because of the power companies own particularity, on the one hand having the issues of selection itself of operational risk assessment indexes, and there is also the problem of index evaluation with strong subjectivity. Current evaluation methods are lack of utilization of the past historical as well as lack of forward-looking. Therefore, in this paper, the analytic hierarchy process and fuzzy set theory are introduced into the assessment of operations risk of power companies to construct assessment index system of the electricity enterprise operational risk. The new index system both can take full advantage of the historical data and are forward-looking, so as to effectively improve assessment, monitoring and early warning of operational risk for the power companies.

\section{The Construction of operations risk index system of electric power enterprises}

Figure 1 shows the main flow of constructs evaluation index system in this paper. As can be seen from Figure 1, after determining the index set, we need to select appropriate evaluation criteria and methods, and determine the evaluation value of each index by Delphi method to obtain evaluation results. Finally, use computational methods to analyze the results, through continuous revision and verification, and ultimately form a suitable evaluation index system.

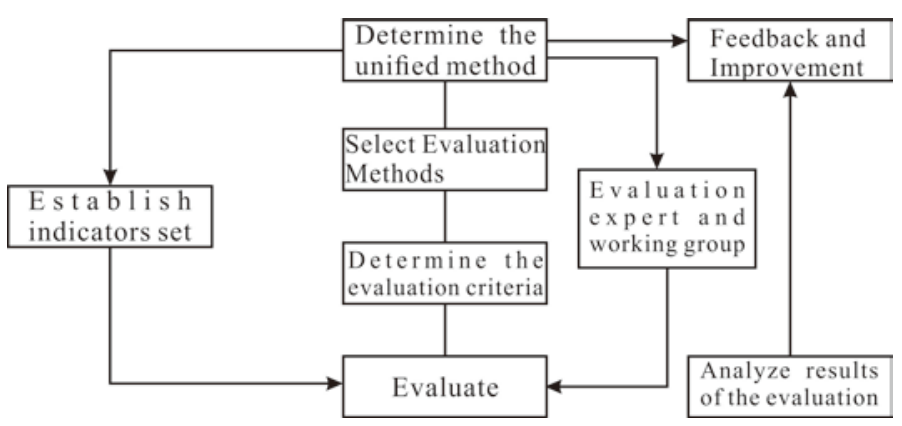

Figure 1. Flow of operations risk index system of electric power enterprise

We are on the basis of the actual conditions of the power companies operations, according to the Delphi method, invite 30 experts to select and score for the indicators set. Then determine risk assessment indicators, and build a complete set of risk assessment system of power enterprise.

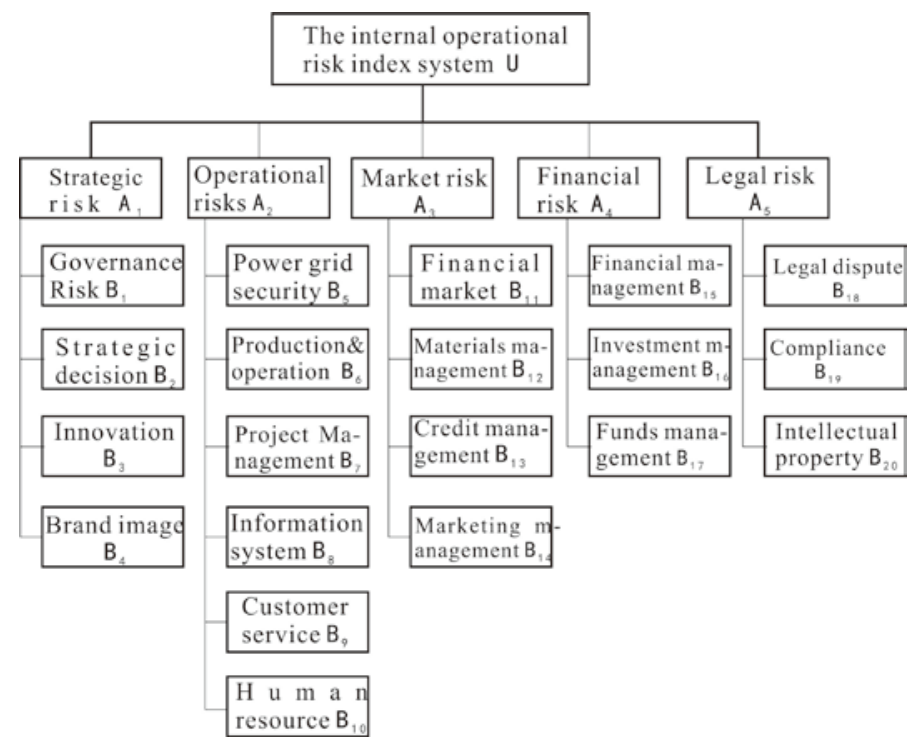

Figure 2. Operation risk index system of electric power enterprises

According to the characteristics of electric power enterprise, risk assessment system of operations can be divided into five categories: strategic risk, operational risk, market risk, financial risk and legal risk, and establish corresponding evaluation rules for each level. List the three levels index system of power companies operational risk evaluation below. This evaluation index system 
is to determine the index evaluation values by expert scoring ways, and then come to the evaluation results.

After determining the index set, an important task is how to build suitable mathematical models and methods to determine the scope of the membership of each index, quantitatively and qualitatively evaluate according to different attributes, and finally get index system of electric companies operations risk assessment, so as to provide decision-making reference to managers and investors.

\section{Operational Risk Assessment Method of Electric Power Enterprise}

To assess operations risk of electric power enterprise should study not only external factors, but also the relationship between the various indicators. The whole evaluation system is fuzzy and some indicators are difficult to describe with certain quantitative relationship, thus we take comprehensive evaluation of combining analytic hierarchy process and fuzzy set theory to qualitative and quantitative evaluate operational risk of power companies. The method is consists of the following steps:

1)Use analytic hierarchy process to were determine weights of indicators in different hierarchys

a. Establish the hierarchy structure of rating indicators

Divide various factors that impact assessment into several levels from top to bottom according to different attributes, while each element on the same level belongs to factors on the upper level as well as dominates the next level factors. AHP requirements is generally divided into three levels, namely the target layer (the top), the criteria layer (intermediate layer) and index layer (the lowest).

b. Structure judgment matrix

Judgment matrix indicates the relative importance between factors of present level that are related to a factor of the previous level. In this paper, use the 1-9 scale to assign the degree of importance, and specific meanings are in the table below:

Table 1 1-9 scale specific meaning

\begin{tabular}{|l|l|l|}
\hline scale & definition & specific meaning \\
\hline 1 & Equally important & Two factors, with the same importance \\
\hline 3 & slightly important & One of two factors is slightly important \\
\hline 5 & obviously important & One of two factors is obviously important \\
\hline 7 & highly important & One of two factors is highly important \\
\hline 9 & extremely important & One of two factors is extremely important \\
\hline $2 、 4 、 6 、 8$ & adjacent scale mid-values & The scale between two adjacent targets \\
\hline reciprocal & converse comparison & $\begin{array}{c}\text { If the scale factor of comparing A with B is i, } \\
\text { thus the scale of B compared with A is } 1 / \mathrm{i}\end{array}$ \\
\hline
\end{tabular}

c. Calculate weighting of different hierarchy factors

There are many ways to obtain the maximum eigenvalue of judgment Matrix and corresponding orthonormal eigenvector, such as the square root method and ANC. We use the square root method here, and the main steps are as follows:

(1) calculate $n$-th root of product of all elements in each row of $n$ factorial judgment matrix $P$ to obtain vector $V=\left[V_{1}, V_{2} \ldots V_{n}\right]^{T}$, where $V_{i}=\sqrt[n]{\prod_{i=1}^{n} a_{i j}}(i=1,2,3, \cdots, n)$; (2) normalize the vector $\mathrm{V}$ to give the corresponding eigenvectors, which is the relative weight vector

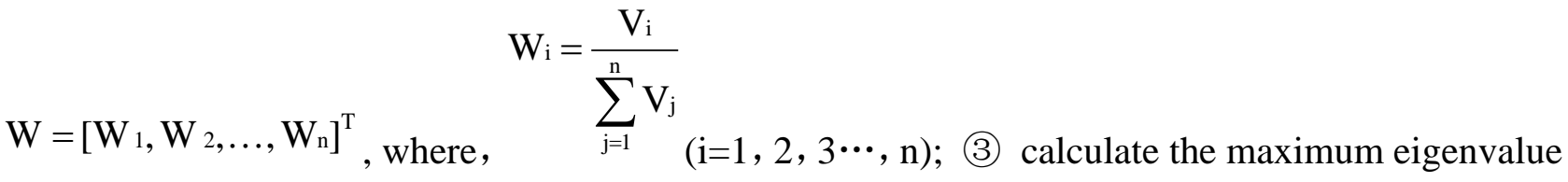
of judgment matrix $\mathrm{P} \quad \lambda_{\max }=\frac{1}{\mathrm{n}} \sum_{\mathrm{i}=1}^{\mathrm{n}} \frac{(\mathrm{PW})_{\mathrm{i}}}{\mathrm{W}_{\mathrm{i}}}(\mathrm{i}=1,2,3 \cdots, \mathrm{n})$, where $(\mathrm{PW})_{\mathrm{i}}$ is the $\mathrm{i}$-th component of the column vector PW that is obtained by the weight vector $\mathrm{W}$ right multiplying judgment matrix $\mathrm{P}$. 
$\lambda_{\max }$ will be used to test the consistency of judgment matrix.

Consistency test of judgment matrix

Since the judgment matrix is artificially endowed with a certain amount of subjective judgment, the judgment matrix that is actual established often does not have complete consistency, so it is necessary to test consistency to evaluate the reliability of the judgment matrix. The method is as follows:

Calculate the random consistency index $\mathrm{CI}: \mathrm{CI}=\frac{\lambda_{\max }-n}{n-1}$, where $\lambda_{\operatorname{ma}}$ is the maximum eigenvalues of judgment matrix and $\mathrm{n}$ is the order of judgment matrix. Calculation consistency ratio CR: CR = CI / RI, where RI is the average random consistency index and its value is in Table 2 .

Table 2 Mean Random Consistency Index (RI)

\begin{tabular}{|c|c|c|c|c|c|c|c|c|c|}
\hline order & 1 & 2 & 3 & 4 & 5 & 6 & 7 & 8 & 9 \\
\hline RI & 0 & 0 & 0.58 & 0.90 & 1.12 & 1.24 & 1.32 & 1.41 & 1.45 \\
\hline
\end{tabular}

When the consistency ratio $\mathrm{CR} \leq 0.1$, it is considered that consistency of judgment matrix is acceptable; when $\mathrm{CR}>0.1$, it is considered that judgment matrix should be appropriately amended.

Establish fuzzy evaluation matrix

Fuzzy comprehensive evaluation is a comprehensive evaluation method based on fuzzy mathematics for solving the problem of uncertainty.

The classification of Evaluation and Assessment

The evaluation index directly adopt the factors of the risk index system that previously build to compose set $U=\left\{U_{1}, U_{2}, \cdots U_{n}\right\}$ that contains $n$ index factors. Then compose evaluation set $V=\left\{V_{1}, V_{2}, \cdots V_{m}\right\}$ that $m$ kinds of evaluation grades that may exist in each indicator factors $U_{i}$ corresponds to

Structure evaluation matrix

First, invite k experts to constitute a evaluation team, and then evaluate factor $U_{i} \quad(i=1,2.3, \ldots, n)$ the of the index factor set $U$ to get a corresponding comment rating $V_{J}$ (j=1,2,3,..., m). After finding the mean of the evaluation results of statistical factors $U_{t}$ which namely is the number of its corresponding evaluation level, construct fuzzy subsets $R_{i}=\left\{\mathrm{r}_{\mathrm{i} 1}, \mathrm{r}_{\mathrm{i} 2}, \mathrm{r}_{\mathrm{i} 3} \cdots\right\}$ of factors $U_{i}$. Similarly, fuzzy matrix can be obtained ranging from set $\mathrm{U}$ to set V:

$$
R=\left\{R_{1}, R_{2}, R_{3}, \ldots, R_{n}\right\}=\left(r_{i j}\right)_{n \times m}=\left[\begin{array}{cccc}
r_{11} & r_{12} & \ldots & r_{1 m} \\
r_{21} & r_{22} & \ldots & r_{2 m} \\
\ldots & \ldots & \ldots & \ldots \\
r_{n 1} & r_{n 2} & \ldots & r_{n m}
\end{array}\right]
$$

where $R_{I J}$ is membership grade that the i-th index factor corresponds to the $\mathrm{j}$-th comment rating $\mathrm{V}$, and after its normalization, make $\sum_{i=1}^{n} r_{i j}=1$.

Fuzzy Synthesis and Comprehensive Evaluation

According to Indicator weight vector $\mathrm{W}$ and fuzzy matrix $\mathrm{R}$ that we previously obtain by AHP, use formula $Y=W^{t} \times R$ to synthesize fuzzy matrix and obtain its comprehensive evaluation result. In the end, based on the principle of maximum membership degree, analyze and process the results of the comprehensive evaluation.

\section{Empirical Analysis}

Based on fuzzy analytic hierarchy method that is set forth above, we use the data of a electric power enterprise to perform an empirical analysis of the electric power operational risk assessment 
index system.

First, according to the power companies operational risk index system constructed on Figure 1, invite 30 experts (10 external experts, 10 in-house experts, 10 electric power enterprise managers). Ask experts based on their knowledge and experience and according to Table 1-9 scale meaning to judge and assign for the relative importance of each indicator in each level on index in upper level, to determine the judgment matrix of pairwise comparison, as shown in Figure 3.

\begin{tabular}{llllll}
\hline 0 & $A_{1}$ & $A_{2}$ & $A_{3}$ & $A_{4}$ & $A_{5}$ \\
$A_{1}$ & 1 & 3 & $1 / 5$ & 3 & 2 \\
$A_{2}$ & $1 / 3$ & 1 & 2 & 3 & 2 \\
$A_{3}$ & 5 & $1 / 2$ & 1 & 4 & 3 \\
$A_{4}$ & $1 / 3$ & $1 / 3$ & $1 / 4$ & 1 & 4 \\
$A_{5}$ & $1 / 2$ & $1 / 2$ & $1 / 3$ & $1 / 4$ & 1 \\
\hline
\end{tabular}

Figure 3 judgment matrix of pairwise comparison

An index weight vectors of primary index can be drawn from judging matrix operations: $\mathrm{U}=\left[\begin{array}{llll}0.26 & 0.36,0.15,0.23,0.1\end{array}\right]$.

By the same method, secondary indicators judgment matrix can be obtained, and secondary index weight vector can be drawn from the judgment matrix.

Calculate judgment matrix maximum eigenvalue $\lambda_{\max }=\frac{1}{\mathrm{n}} \sum_{\mathrm{i}=1}^{\mathrm{n}} \frac{(\mathrm{PW})_{\mathrm{i}}}{\mathrm{W}_{\mathrm{i}}}$ and consistency index CI $\lambda_{\max }-n$

$=n-1$, and then result in consistency ratio CR: CR $=$ CI / RI. Judgment matrix consistency ratio: $\mathrm{CR}=0.0005$, and CR of all judgment matrixes above the second-order is less than 0.1 , therefore, judgment matrix passes consistency test and the results are reliable.

Learn from the evaluation grading standards of enterprise risk management in financial industry, we establish an assessment grading standard of electric power enterprise operational risk with five grade level, $U=$ excellent, good, fair, poor, very poor $\}, V=\{100,90,80,7060\}$.

Invite 30 experts (10 external experts, 10 in-house experts, 10 electric power enterprise Managers) to compose the evaluation team to assess each index of assessment system of power companies operations risk, and obtain fuzzy evaluation matrix R of index A1. Similarly, obtain evaluation matrix of index A2-A5.

$$
\mathrm{R}=\left\{\begin{array}{lllll}
0 & 0 & 1 & 0 & 0 \\
1 & 0 & 0 & 0 & 0 \\
0 & 0.2 & 0.8 & 0 & 0 \\
0 & 0 & 1 & 0 & 0
\end{array}\right\}
$$

Calculate from the bottom layer stepwise in Figure 2, ultimately comprehensive evaluation matrix in evaluation index system of electricity market can be obtained. According to the principle of maximum membership degree, the evaluation grade that the largest element in the matrix corresponds to is the comprehensive evaluation level of power companies' operational risk. Calculate and normalized based on simulated data, we can obtain evaluation results of electric power enterprise operations risk, $\mathrm{B}=(0.33,0.021,0.59,0.043,0.016)$. Introduce fractional set $V=\left\{V_{1}, V_{2}, \cdots V_{m}\right\}=\{100,90,80,70,60\}$, then comprehensive evaluation score is $\mathrm{U}=\mathrm{B} * \mathrm{~V}=$ 86.06. According to the evaluation set, the rating of electric power enterprise operations risk is "Medium".

This comprehensive evaluation shows that there are certain risks in the power companies operating, thus we need to take appropriate risk management strategies on upgrading the risk management for the status quo of this level risk management. The coping strategies are: first of all, based on the risk accidents that actually occur and present potential risks, classify them by contrasting specific risk indicators of operational risk index system; secondly, analyze the frequency and distribution of potential risks accidents and risk from it; finally, based on the above analysis, 
take targeted risk prevention strategies for different categories, and improve the current risk management processes and methods. So that it can achieve closed-loop operating results of management process, and then achieve sustained improvement of risk management performance.

A particular problem which should be noted in this improvement process of risk management performance is that, enterprises' resources are limited. They cannot monitor every risk factor to be faced. Therefore, companies must the most reasonably make the use of limited resources, and put them into the most important risk factors for planning use, in order to maximize its effectiveness. On the other hand, there exists a problem of comparing a risk management costs and benefits of risk. So for the promotion of risk management performance, it should focus on operational risk indicators and accident-prone risk areas that occupy important weights in operational risk index system, so we can achieve the most efficient risk management effectiveness.

\section{Summary}

In this article, we apply AHP and fuzzy set theory to the field of electricity business operations risk evaluation, and give full play to the superiority of fuzzy comprehensive evaluation method for processing qualitative and quantitative data. The electricity business operations risk evaluation system that is constructed in this paper can help managers and investors more objectively judge the level of enterprise risk management, and effectively prevent and resolve potential risk in power enterprise operation and management through risk identification and analysis, risk control, etc.

Besides, enterprise operational risk widely presents in any industry and any enterprise, managing it is not the management and control activities that are independent from the business activities of the companies. In contrast, operational risk management is throughout the entire process of business activities. Therefore, it requires corporate management not only to establish a sense of risk management, but also to make the full use of various means to enhance their risk management level on the basis of establishment of scientific risk assessment system. Operational risk management system enables companies to form a working mechanism that guards against the risk in the daily operations, so that risk factors can be effectively controlled in operational process to avoid causing a significant loss to the enterprise and improve enterprise operational performance.

\section{Acknowledgement}

In this paper, the research was sponsored by STATE GRID Corporation of China. The issue is "The study and application of Company Management Innovation and Performance Evaluation and key technologies”.

\section{References}

[1] Wen Wang, Dong Wang. Evolution and Prospect of Enterprise Risk Management Theory [J]. Auditing Research, 2010(4):96-100.

[2] Chaoying Lin, Zhigang Huang, Dejin Shi. Influence of Monetary Policy on Enterprise Risk Management [J]. FINANCE FORUM, 2014(6):38-45.

[3] Hoyt R E, liebenberg A P. The value of enterprise risk management [J]. Journal of Risk and Insurance, 2011, 78(4):795-822.

[4] Hanfang Li, Zhongfu Tan, Chengwen Wang. Risk Structure Analysis of Electric Power Enterprises Based on the Interpretive Structure Model In Electricity Market Environment [J]. Power System Technology, 2007(13):59-65.

[5] Jianhua Gong, Liping Lei, Minxia Wu, Cunbin Li. Comprehensive Evaluation of Power Companies Based on TOPSIS Method And Gray Relational Degree [J]. Guangdong Electric Power, 2014(2):7-10. 